\title{
Os cães com depressão e os seus humanos de estimação
}

Depressed dogs and their human pets

Jean Segata

\section{(2) OpenEdition}

12 Journals

Edição electrónica

URL: http://journals.openedition.org/aa/216

DOI: $10.4000 /$ aa. 216

ISSN: 2357-738X

\section{Editora}

Programa de Pós-Graduação em Antropologia Social (UnB)

\section{Edição impressa}

Data de publição: 1 dezembro 2012

Paginação: 177-204

ISSN: 0102-4302

\section{Refêrencia eletrónica}

Jean Segata, «Os cães com depressão e os seus humanos de estimação», Anuário Antropológico [Online], v.37 n.2 | 2012, posto online no dia 01 outubro 2013, consultado o 28 abril 2021. URL: http:// journals.openedition.org/aa/216; DOI: https://doi.org/10.4000/aa.216

\section{(c) $(1)(9)$}

Anuário Antropológico is licensed under a Creative Commons Atribuição-Uso Não-Comercial-Proibição de realização de Obras Derivadas 4.0 International. 


\title{
Os cães com depressão e os seus humanos de estimação
}

\author{
Jean Segata \\ UFSC \\ UNIDAVE
}

\begin{abstract}
"Tenho uma química ruim com os animais.
Acho que são mudos de alma.

Não os odeio, mas não consigo suportá-los porque não aprendi a negociar com eles.”
\end{abstract}

Gabriel García Márquez

Na sorte das discussões contemporâneas, a humanidade dos animais de estimação é um tema controverso. Até chegarem ao posto de nossos bebezinhos, lindinhos da mamãe, fiéis companheiros, e viverem em nossos lares, motivarem manifestos ou se tornarem o foco da atenção de gestos médicos e estéticos, houve um longo caminho a ser percorrido. Isso incluiu, necessariamente, uma série de investimentos que acalmaram ou que tentaram tornar invisíveis as suas pulsões naturais - o que, historicamente, tratamos por modulação ou domesticação. Contudo, hoje isso aparece sob formas mais complexas: latir, rosnar, urinar, mostrar as garras foram algumas das vantagens evolucionárias que permitiram que cães e gatos garantissem a sua alimentação ou protegessem o seu território e a sua prole. Mas isso não combina com a decoração da sala de estar de nenhum apartamento, o que faz com que os animais que se comportam dessa forma sejam diagnosticados como "doentes mentais" - agressivos, ansiosos ou depressivos - e medicados com psicotrópicos (Vlahos, 2008). Igualmente, as suas habilidades de captura de outros animais, devorados em banhos de sangue, foram substituídas pelas tigelas de ração industrializada, com o balanço certo de componentes que fazem produzir fezes sem odor e de consistência apropriada para não sujar o chão. E nem faz muito tempo que cães e gatos de estimação morriam de velhos. Hoje, eles são obesos, sofrem com o colesterol, o diabetes, a pressão alta, os problemas renais e, mais recentemente, com a ansiedade e a depressão. 
De um modo geral, este artigo aborda uma série de negociações em torno da humanidade dos animais de estimação. Dessa forma, eu procuro fazer aparecerem certos "problemas de encaixe" no que diz respeito aos modos como os humanos e os animais se identificam, se distinguem ou se relacionam, tomando-se como caso específico o diagnóstico e o tratamento da depressão de uma cachorra de estimação. Com isso, em voga, aparece a ideia de que humanizamos os animais para que com eles possamos nos relacionar - e então temos os animais de tração, carga e transporte, outros com os quais nos divertimos em jogos e caçadas ou aqueles que escolhemos para a nossa companhia. No entanto, cães vestidos como crianças, gatos no colo, chamados de "meu menino", animais abatidos para o consumo ou dependentes de fluoxetina formam o protótipo de uma imagem controversa, que se traduz tanto em sensibilização como em reprovação, justiça ou exagero, dever ou heresia. Igualmente, o que vem como reflexão geral é aquilo que cabe na provocação de que a chave que aciona essas medidas se nutre da suposição de uma igualdade moral - a de que os animais também são gente. Mas o que eu procuro mostrar neste trabalho é que muitas dessas diretivas se valem de uma equivalência biológica - a de que os humanos também somos animais, ou seja, a crescente humanização dos animais não se nutre apenas de equivalências culturais, mas igualmente daquelas naturais, e a antropologia não pode ficar indiferente a isso. ${ }^{1}$

\section{Uma nova epidemia}

Tirei o jaleco branco e parei no balcão para algumas anotações. Eu estava na loja de Marcos, uma pet shop com clínica veterinária da cidade de Rio do Sul, no interior de Santa Catarina. Eram quase onze, e dali a pouco eu iria direto para a academia, ainda antes do almoço.

- Eu não vou deixar ela aqui, hoje é sexta.

A voz da mulher ao celular vinha da sala de espera. Apenas olhei. Dado a hora, eu não queria me envolver. No sofá, uma poodle grande, com meio corpo deitado sobre a sua perna.

- Sim, vamos ver o que esse aqui diz. Qualquer coisa eu volto pro trabalho hoje à tarde. Acho que não é depressão.

Olhei de novo. Ela continuava ao celular, mas sem falar. Passei direto e fui até a sala de Marcos e esperei no lugar de sempre. Na mesma hora ele veio da internação e convidou-as a segui-lo.

- Bom dia.

Marcos fez os cumprimentos, apontou para mim e disse que eu acompanhava os trabalhos. Ela me olhou com um sorriso e balançou a cabeça e se apresentou como Bia. 
-Então, como é o nome dessa menina? - ele perguntou, olhando para a poodle.

- É Pink. Mas eu não sei o que ela tem, anda meio triste - respondeu a mulher.

- Vocês já consultaram aqui?

- Não.

- Quantos anos ela tem?

- Nove.

- Alguma coisa diferente nos últimos dias: não come...?

- Eu sempre fui no Dr. Roberto e ele e o outro que trabalha junto disseram que ela está com depressão, mas eu não acredito nisso: minha amiga na contabilidade é depressiva e não se comporta assim. A Pink geme a noite toda, uiva acho que já perdeu alguns quilos, não vai direito no banheiro, se coça toda e fica assim, toda tristinha. Eu tenho medo de que ela esteja doente de novo.

- O que ela tinha?

- Com 6 anos o Dr. Roberto curou ela de um tumor na garganta. Ele operou e depois fez quimioterapia por um tempo. Curou tudo, mas pode ter voltado, não é?

Marcos anotava tudo no prontuário, no computador. Eu continuava em silêncio, escrevendo também. Em seguida ele se levantou e pediu que Bia levasse Pink até a mesa de exames. Como de costume, eu fui ajudar. A cachorra mal se mexia e Marcos puxou suas pálpebras, olhou as gengivas, apertou o abdome em movimentos de massagem e com o estetoscópio ouviu seu coração e pulmões. Depois, ele a puxou pela nuca e me olhou: a pele demorou a se restabelecer no lugar: estava desidratada, eu já havia aprendido isso. E ele voltou para a mesa fazendo sinal para que Bia fosse também.

- Ela está bem debilitada. Mas ainda é difícil dizer o que é. Eu vou precisar fazer alguns exames.

Bia abaixou a cabeça um pouco e ficou olhando para Pink. Tudo indicava a sua internação.

- Tudo bem. Mas será que é depressão? Isso pode?

- Eu farei uma biópsia para ter certeza do tumor. Acho difícil ter voltado, mas pode acontecer. Se não for isso, pode ser que seja depressão mesmo. Ela fica sozinha?

- Enquanto eu estou na contabilidade, sim. Eu chego depois das seis.

- Pode ser isso.

- Mas em cachorro? A minha amiga que tem depressão fica até dopada com "o faixa preta" que toma. Tem vezes que ela tem que ir pra casa, se não dorme no escritório. A Pink vai ficar assim?

- Não. Caso seja isso mesmo, eu vou receitar a dosagem certa de um composto 
de fluoxetina - tudo de acordo com o peso e as medidas dela. Daí, você manipula na Gemballa. ${ }^{2}$ Enquanto isso, ela precisará ficar aqui até, pelo menos, a segunda; ela está muito desidratada, e nisso aproveito para fazer os exames.

- Tá, mas a Gemballa tem remédio pra depressão de cachorro?

- Sim.

- Nossa, eu não fazia ideia, então, isso existe mesmo.

No sábado pela manhã, eu voltei. Pink havia passado a noite tomando soro para se reidratar e parecia melhor. Depois que Bia saiu de lá no dia anterior, ajudei Paula com alguns exames e procedimentos clínicos. Foi com grande insistência de Marcos que Bia deixou a poodle internada.

Enquanto a contadora ainda estava na loja, ele não fez nenhuma intervenção mais invasiva na cachorra, apenas ficou repetindo alguns testes simples, como bater palmas próximo da sua orelha ou passar o bloco de receitas na frente dos seus olhos, avaliando suas reações aos estímulos externos. Segundo Bia, a cachorra já havia perdido quase metade do peso nas últimas semanas. Ela contava que, mesmo ficando fora o dia todo, percebia que Pink não se alimentava, pois a ração e a água permaneciam da mesma forma que ela deixara, pela manhã. Em poucos minutos, Paula, filha de Marcos e récem-formada em veterinária, repetiu várias das perguntas que Marcos também havia feito - e imaginei que fosse alguma estratégia para confirmação de respostas ou para a identificação de contradições. Ao final, a dona questionou novamente se era depressão, como já havia ouvido de outros veterinários, e que agora se somava à suspeita de Marcos. Mesmo assim, para tirar ainda uma última hipótese de cogitação, ela perguntou se poderia ter sido um bombom, porque a mãe dela, às vezes e às escondidas, dava chocolates e outras guloseimas para a cachorra. Os veterinários quase descartaram isso de imediato, mas avaliariam uma possível intoxicação alimentar. Eu ouvia tudo aquilo com certo entusiasmo - fazia tempo que eu saía da loja com a sensação de que "nada era interessante", mas a história da depressão mexera comigo.

Depois que Bia saiu, na mesa de mármore, Paula e eu passamos ao exame de Pink. Ela mediu a febre, inserindo o termômetro no ânus da cachorra, tomou os batimentos cardíacos com um estetoscópio, e repetiu alguns dos testes de Marcos, passando o dedo de um lado para outro em frente aos seus olhos para ver se ela acompanhava os movimentos, puxou a pele da sua nuca e fez toques e pequenas massagens ao longo do corpo. De tão debilitada, mesmo nos gestos mais bruscos, Pink não ensaiava nenhuma reação, de modo que eu nem precisei segurá-la, como já fazia por costume durante os exames.

- Não me parece intoxicação, não, comentou Paula. Nós vamos tirar uma 
amostra de sangue e encaminhar para o laboratório. Vou pedir tudo, daí a gente já vê se é alguma intoxicação ou qualquer outra coisa, sentenciou.

Marcos voltou para a sala com uma gilete nova e raspou os pelos no entorno do tornozelo de uma das patas dianteiras de Pink, contando com a ajuda de Paula para segurá-la. Segundo ele, ali era o melhor lugar para a coleta do sangue, pois era mais fácil de localizar as veias. Paula segurou a cabeça e a pata da cachorra, enquanto ele "achava a veia" para a coleta de uma seringa cheia. Em seguida, ele colocou o conteúdo da seringa em um pequeno recipiente cilíndrico, como um Tubo de Becker, mas com tampa plástica para proteger o líquido. Balançou o tubo com sangue de um lado para outro, e definiu que ele estava numa consistência normal - ou pelo menos nos seus dizeres, não estava contaminado por carrapatos.

- Se ela estivesse contaminada por carrapatos, o sangue estaria assim "uma coisa".

Na hora, eu não sabia ao certo o que seria "uma coisa", mas fiz por minha conta uma imagem de algo meio gelatinoso ou com alguma consistência diferente daquela líquida. Na verdade, fui pesquisar e descobri que ele estaria mais "apagado", o que seria um indicativo da babesiose canina, uma doença parasitária transmitida por carrapatos que pode gerar a anemia, perda de peso, fraqueza ou estados depressivos, até chegar à morte (Corrêa et al., 2005). Estes eram alguns dos sintomas que compunham o quadro de Pink.

Enquanto Marcos preparava a amostra, separando algumas gotículas do sangue sobre uma lâmina de microscópio, e etiquetando o tubo com a identificação da cachorra, Paula pediu que eu ajudasse com o soro. De início, ela quis aproveitar a mesma área já depilada por Marcos para procurar outra veia e colocar a agulha do soro. Mas antes de começar a furar a pata de Pink novamente, Marcos sugeriu que ela fizesse isso no outro lado, para não gerar tanto trauma em um só lugar. Então, nova depilação e, desta vez, por minha conta, pois Paula se disse meio desajeitada com a gilete. Agora Pink já ensaiava reações, e Paula, que dizia que ela estava ficando estressada, foi rápida com a agulha e com a sonda. Enquanto isso eu tentava distinguir uma veia de uma artéria, apenas olhando a diferença de cores, como já haviam me ensinado, mas eu não conseguia notar a diferença.

Terminado o processo de encaixar os pequenos tubos, Paula verificou o fluxo exato do soro, ajustando uma válvula plástica, perto da bolsa de um litro. Para evitar a entrada de ar nos tubos, Paula ainda fincou no alto da bolsa de soro, no intervalo entre o líquido e o topo da embalagem, a agulha antes usada para encontrar a veia de Pink. Na sequência, passamos a um enorme curativo, 
envolvendo de uma só feita, a pata, a "agulha de plástico" e parte do tubo que conduzia o líquido, de modo a manter tudo imobilizado caso Pink se mexesse bruscamente durante a internação. Em seguida, ela tomou a cachorra nos braços e pediu que eu ajudasse a levar o soro, sempre em um ponto mais alto que a cachorra, para que o fluxo de soro fosse mantido e para que o ar não entrasse no tubo. Na sala de internações, Pink ocuparia uma gaiola e eu colocaria o soro em um suporte metálico próprio para este fim.

- Agora a nossa "deprimidinha” vai ficar assim um tempinho, até a próxima rodada, disse Paula, com um meio sorriso.

A "próxima rodada" seria a biópsia. Como não encontrou nenhuma alteração aparente no volume da região do pescoço da cachorra, Marcos decidiu não fazer intervenção cirúrgica. Segundo ele, não se justificaria “cortar” o animal se era possível a coleta por aspiração. A biópsia aspirativa é um método de coleta de material que se faz por meio de uma agulha na região do processo tumoral, com ampla utilização entre humanos, e que tem se tornado cada vez mais comum na medicina veterinária, justamente pela facilidade com que o diagnóstico pode ser realizado (Cunha, 2009).

Contando que a biópsia já permitiria o exame celular, Marcos ainda se encarregaria de mais algum morfológico e de fazer o raio-x da cachorra para avaliar alguma metástase. A sua preocupação era a de deixar isto pronto logo, pois no fim de semana não havia como dar encaminhamento ao exame. Enquanto eu ajudava Paula com os procedimentos finais da internação de Pink, Marcos já preparava lâminas com a amostra retirada da cachorra, que seriam despachadas para Belo Horizonte (MG) ainda naquela tarde, via Sedex 10.

- Faz um bom tempo que eu trabalho com um laboratório de lá. Eles têm excelência neste tipo de exame, são rápidos e precisos. Segunda-feira a amostra chega lá e no mesmo dia eles já vão me enviar o resultado por e-mail.

Para mim, que queria sair mais cedo e fazer meus exercícios (já era passada meia hora da tarde), e os veterinários sabiam qual era a academia que eu frequentava, pediram-me que levasse a amostra de sangue até o laboratório que ficava próximo a ela. Ao final da tarde, um deles passaria lá para pegar o seu resultado. Peguei minha mochila lá no armário da sala de banho e tosa, temporariamente desativada, e guardei a encomenda com cuidado, entre minhas roupas de academia.

- Só vou te pedir pra não virar isso, nem quebrar, nem perder, dizia Paula rindo.

Marcos saiu na mesma hora - ia almoçar e levar a amostra da biópsia aos Correios - e eu saí rindo também, com o pensamento no tubo cheio de sangue 
de cachorro com suspeita de depressão para ser entregue no mesmo laboratório onde eu fazia os meus exames rotineiros.

Minhas idas para a academia eram recomendações médicas. Segundo ele, eu andava muito estressado, ansioso, preocupando-me em demasia com o trabalho e me alimentando mal, acumulando peso, muitos afazeres, hábitos sedentários e mais uma lista de problemas que ele havia capturado em minhas poucas respostas às suas perguntas. Recomendou-me então exercícios frequentes, um tempo para relaxar - idas à academia, para manter a regularidade das atividades e contar com orientações.

De alguma maneira aquilo foi decisivo para a pesquisa. Parecia irônico, mas um pouco antes eu ouvira Marcos falar para Bia que ela deveria se envolver menos com o trabalho, de modo a permitir mais tempo livre com Pink, que deveria alimentá-la mais adequadamente e levá-la para exercícios no parque da cidade, porque o apartamento fechado a poderia deixá-la estressada, ansiosa e com a saúde ruim. Assim, desde que Pink apareceu na loja, passei a focar minha atenção nos casos em que, na falta de uma origem mais precisa para certos estados com os quais certos animais se apresentavam, era imputado a eles o diagnóstico de depressão.

Philippe Pignarre (2001:21) situa bem as controvérsias em torno deste tema, especialmente a partir de algumas transformações da psiquiatria ocidental. Entre elas, o laço com a biologia e o uso do DSM:

Le DSM est avant tout un outil para établir le consensus: oublions tous les sujets qui fâchent (les causes des troubles mentaux) pour nous concentrer sur les points d'accord (les manifestations visibles des différents troubles) Son mode de rédaction en témoigne: des groupes des psychiatres américans se réunissent pendant des annés pour établir par concensus les critères permettant de classer les patients. Le DSM n'a uniformisé la manière de poser un diagnostic que parce qu'il a d'abord uniformisé les psychiatres dans la manière d'observer les patients.

A questão que o autor coloca é a de que, desde o DSM, aparece a imposição de uma depressão universalizada, e por isso ele classifica como epidemia, já que, no mundo psiquiátrico ocidental, ela se baseia nos mesmos sintomas consensuados na APA. A uniformização do olhar do psiquiatra, nos moldes da associação americana, passou a definir e a diagnosticar a depressão a partir do reconhecimento de pelo menos cinco sintomas por um período igual ou superior a duas semanas. Pignarre (2001) elenca estes sintomas: "tristeza excessiva”; "perda 
de interesse, incapacidade de agir"; "problemas de apetite”; "problemas com o sono"; "agitação ou desaceleração"; "fadiga, perda de energia”; "culpabilidade excessiva"; "dificuldade em se concentrar" e "vontade de morrer".

Imagine-se então como antropólogo em trabalho de campo numa pet shop, com o compromisso iminente da escrita de uma tese, e dividido entre a pesquisa e o trabalho na universidade e a organização de documentos e providências burocráticas para sair do país com o objetivo de um estágio doutoral. Eu estava, fazia algumas semanas, experienciando alguns daqueles sintomas. Na mesma via, Pink também os aparentava e isto nos aproximou em um primeiro momento - mesmo sendo ela uma cachorra, e eu um humano. Para o alívio do seu sofrimento, o veterinário pediu que se dessem condições de ela mudar as suas rotinas. Igualmente, para o alívio dos meus problemas, o meu médico fez as mesmas recomendações, de modo que a humanidade de Pink parecia tão evidente quanto a minha. Mas isto não bastava: para o seu tratamento, ela precisaria de fluoxetina, tanto quanto eu precisava de sibutramina. Desde Descartes, a ciência e a filosofia entendem a subjetividade e a experiência como partes que compõem o mundo privado, de difícil acesso e análise. Mas este não era mais um problema - por sorte, a nossa natureza era equivalente. Descortinados, ambos, da nossa humanidade, sobrávamos os dois, feito bolos de compostos orgânicos e inorgânicos em desalinho. Este é um dos efeitos entre o casamento da psiquiatria com a biologia, apontado por Pignarre (2001, 2006): ele divide subjetividade e fisicalidade e age na segunda para obter respostas na primeira.

Azize (2010:03) também pontua isto ao se debruçar sobre o que ele chama de "nova ordem cerebral". Para ele:

Um vocabulário relacionado às "novas ciências do cérebro" - neurônios, neurotransmissores, sinapses, serotonina etc. - começa a fazer parte do acervo semântico do qual o público leigo lança mão em seu cotidiano para falar dos mais variados temas que dizem respeito ao comportamento e aos sentimentos humanos. Estamos atravessando um processo de popularização desse tipo de saber, assim como já vivemos uma popularização de saberes ligados aos conhecimentos "psi", como inconsciente, ego, ato falho etc. Ecos de uma "cultura psi” convivem hoje de forma complexa com um discurso no qual o cérebro tem preeminência sobre a mente; ou melhor, a mente é um epifenômeno do cérebro, uma consequência direta de sua atividade química e elétrica. Trata-se aqui de pensar o papel da difusão científica nesse processo. Mas também refletir sobre uma mudança mais ampla em termos de visão de mundo, a partir da qual uma noção de pessoa centrada no cérebro começa a fazer sentido. 
A questão que aparece aqui é a de que, para mais além do que sugere Azize (2010) esse novo vocabulário semântico não era apenas acionado para tratar dos comportamentos ou dos sentimentos humanos. Ele dava sentido àqueles do animal humanizado. A bem da verdade, eles permitiam constituir ou reificavam a humanidade de Pink ao mesmo tempo em que faziam aparecer a nossa animalidade - afinal, até podemos questionar a tristeza e a apatia da cachorra e duvidar de uma subjetividade que a singularize entre outras da mesma espécie, mas não podemos negar que ambos temos cérebro e neurotransmissores, com atividades químicas e elétricas que funcionam a partir dos mesmos princípios. No século do cérebro, a animalidade nos uniu. Como continua Azize (2010:07), "novas formas de objetividade e novas formas de subjetividade confundem-se em um discurso que mescla cérebro e pessoas, imagens técnicas e sentimentos, razão e emoção" e, por que não, o humano e o animal.

\section{Coisas de mulher}

Durante o restante de tempo em que fiz o trabalho de campo na loja, apareceu, em média, pelo menos um cão por semana que levaria com ele esse diagnóstico, somando algo em torno de 30 deles. Mesmo que minhas preocupações não tenham sido comprovadas em termos estatísticos, dois fatos chamavam a atenção: o primeiro deles é que há em Rio do Sul dezenas de pet shops e alguns amigos que sabiam de meu trabalho falavam-me que fenômeno semelhante se tornara frequente em outras lojas; o segundo deles é a incidência em cadelas, pois pelo menos dois terços dos casos que acompanhei mais de perto eram de fêmeas de pequeno e médio portes.

Além da loja de Marcos, às vezes eu acompanhava Paula até outra clínica bem próxima, a de Alice, sua amiga e ex-colega de faculdade. Ela confirmou muitos casos de depressão, especialmente pelo fato de que a sua loja possuía uma ênfase especial - era uma pet shop de ginecologia e obstetrícia - onde a maioria dos cães depressivos era representada por cachorras que somavam à depressão o diagnóstico de gravidez psicológica.

A clínica de Alice era de porte bem menor que a de Marcos, e ficava no segundo piso de uma pet shop que tinha outra pessoa como proprietária, ou seja, não se tratava de um único estabelecimento, mas apenas de uma proximidade estratégica. A questão-chave dos seus serviços era a sua especialidade: o foco era o acompanhamento da gravidez de gatas e cadelas, como também o auxílio nos partos ou a aplicação de vacinas anticoncepcionais. Tratava-se de uma "clínica para coisas de mulher", como definia Alice. Mas o seu trabalho era bem mais amplo. 
O grande problema é que as pessoas não planejam a gravidez dos seus animais. Bem, se muitas vezes nem planejam nem para si... Mas eu tenho feito um trabalho de conscientização aqui. Mas é difícil, porque em casa as pessoas até cuidam e não deixam os animais se misturarem ou saírem sozinhos pela rua. Mas nos fins de semana ou nas férias eles saem para passear ou recebem visitas e aí juntam os animais da família e o controle se perde (Alice, em outubro de 2009).

Eu não acompanhei nenhum dos seus procedimentos, mas, pela sua apresentação, a clínica era bem equipada: tinha um aparelho de ultrassonografia, que Alice comprou de "segunda mão" de uma médica ginecologista da cidade, além de dispor de uma sala de cirurgia para partos cesarianos e outra mesa para os partos naturais, acrescido do material clínico e farmacêutico de praxe.

Alguns blogs ou sites de clínicas veterinárias difundem as vantagens do pré-natal animal. Fazendo um sobrevoo nos seus conteúdos, é possível ler recomendações que incluem cuidados com dietas, que devem ter mais ferro para evitar a anemia nas futuras “mamães", exercícios, especialmente aqueles que promovam a desenvoltura abdominal, em favor de partos naturais, além de exames clínicos e hemopatológicos, a fim de evitar surpresas ou complicações, especialmente em casos de gravidez de risco. ${ }^{3}$ Além desses textos, a expressão "mamãe”, para se referir às cadelas e gatas, eu já tomava como comum, pois era desta forma que Paula, Alice ou Marcos tratavam os animais nessas condições. Mas, em certa ocasião, Alice fez questão de me corrigir quando eu perguntei a ela detalhes sobre a prenhez das cadelas. Os detalhes não apareceram, o que veio foi a explicação de que o termo prenhez era inapropriado para os animais de estimação. Como ela colocou, "eles são tão humanos" que "a gente” costuma dizer que elas estão grávidas, por isso as recomendações para ultrassonografia, os exames laboratoriais para a detecção de alguma alteração bioquímica no corpo e, é claro, o que ela apontava ser o mais importante, "cercar a futura mamãe" de todos os carinhos e mimos para "aquele momento tão especial". Mas era nesse ínterim que aparecia a depressão.

$\mathrm{Na}$ literatura médico-veterinária que eu pesquisei, havia pouca associação entre depressão e gravidez psicológica, contudo, nos blogs e em outros sites "não científicos" ou mesmo no discurso de Alice, havia uma correlação bastante pragmática entre elas. De uma forma geral, a depressão aparecia como denotação da fraqueza da cadela - neste caso, uma fraqueza psicológica, associada à "frustração" diante da falsa gravidez ou à "carência" diante da ausência dos "filhotes idealizados". Segundo Alice, 
elas [as cadelas] começam a ganhar barriga, ficam com as tetas inchadas e, quando chega o tempo da cria, se aninham para terem os filhotes. Mas os filhotes não aparecem. É frustrante - imagine o que isso representa para uma mãe que idealiza a chegada dos filhos! [...] Então ficam depressivas. A solução, neste caso, é a aplicação de anticoncepcional ou castração, para a gravidez, e a administração de psicotrópicos à base de fluoxetina, um santo remédio para a depressão (Alice, em outubro de 2009).

O termo veterinário para a gravidez psicológica é pseudociese canina. Também conhecida como pseudogestação clínica ou manifesta ou pseudoprenhez ou falsa gestação. Segundo Lopes e Martins (2005), ela é caracterizada pela "mimetização dos comportamentos pré, peri e pós-parto", acompanhada da "adoção de objetos inanimados ou de filhotes de outras fêmeas, com excessivo carinho, atenção, proteção e defesa". Muitas condições dessas cadelas são de fácil tratamento clínico ou mesmo nem o requerem, pois no final do ciclo o conjunto sintomático tende a desaparecer. Questões mais pontuais são de fácil manutenção, apontadas por Lopes e Martins (2005): trata-se do cuidado com as possíveis diarreias e vômitos, além da produção e da secreção láctea, que podem ser tratadas impedindo-se a ingestão de líquidos por seis ou sete noites e fazendo-se o uso de um colar elizabetano que impeça a lambedura das mamas, o que estimula a prolactina.

Os maiores problemas são aqueles de ordem "psicológica”, já que as cadelas nesta condição podem apresentar agressividade, ganhos de peso pela compulsão alimentar ou anorexia, e a depressão. Nessa situação, há o estímulo às atividades físicas associadas ao uso de medicação. O interessante é que os "tratamentos baseados no uso de estrógenos, progestógenos e andrógenos" e outros esteroides são tomados como "não muito indicados", por conta dos efeitos colaterais. O sugerido são os tratamentos com "agonistas seletivos e não seletivos de dopamina”, entre os quais alguns são indicados para a depressão. Como muitos dos medicamentos propostos não são licenciados para uso veterinário no Brasil, as autoras trazem uma boa lista de equivalentes de uso humano. Mas o ponto é que mesmo as "questões psicológicas" são entendidas, neste caso, como questões físicas - afinal, a fluoxetina, por exemplo, cumpre bem o "seu papel de refazer o balanço neuroquímico cerebral”.

O psicológico aqui segue um entendimento fisicalista, e não metafísico: emoção, subjetividade, identidade ou qualquer equivalente a ele é entendido como próprio da natureza (no sentido de físico, biológico). ${ }^{4} \mathrm{O}$ que se depreende disto, especialmente do modo como a veterinárina colocava a questão, é que 
a depressão canina, com sua incidência maior em fêmeas, não é apenas uma questão de reação à gravidez psicológica, mas sim um problema emocional, que deveria ser tratado quimicamente, pois se referia ao cérebro - mais especificamente, ao cérebro de fêmeas - que é parte da sua natureza e está incluído naquele pacote de "coisas de mulher".

\section{Parecidos o suficiente}

"É tudo igual". Esta era uma resposta bastante pronta para um amplo conjunto de medidas que autorizavam e naturalizavam a utilização de tecnologias médicas, incluindo medicamentos para animais de estimação. Marcos e Paula frequentemente conversavam comigo sobre estes temas. E interessava-me em nossas conversas justamente a naturalidade com a qual elas se desenrolavam, com longas narrativas sobre suas experiências de trabalho em pet shops e clínicas veterinárias. Para elas, o avanço da medicina veterinária e a emergência de cães com depressão eram entendidos como "supernormais".

Foi nesse período que eu procurei os Laboratórios Gemballa, para onde eram encaminhados muitos dos donos de cães depressivos para que encomendassem a manipulação dos medicamentos. Lucas, um dos bioquímicos do laboratório, já era meu amigo há alguns anos, e comecei a envolvê-lo na pesquisa, questionando-o sobre as prescrições de fluoxetina para cães:

Vou ser bem sincero. Tu sabes que agora eu não estou trabalhando nisso, eu sou um dos farmacêuticos responsáveis lá na Gemballa, assino papéis, ajudo nas vendas, mas não estou mais na produção. Tem outros lá que trabalham na manipulação. Mas é simples: para mim, que sou o farmacêutico, não faz diferença nenhuma o objetivo final do medicamento.

[E se ele não funcionar, pelo fato de ser para um cachorro?]

Bem, alguém, antes de mim, já se preocupou com isso, lá no laboratório, lá na indústria, na universidade, alguém se dedicou à pesquisa para saber se ele ia funcionar ou não: fez os testes cegos, tirou as provas de placebo, as contraprovas, enfim, seguiu o protocolo. Então, agora, pra mim, que estou lá na produção comercial e não na pesquisa, não é isso que está em jogo, a coisa é mais direta e objetiva: eu preciso respeitar a fórmula, nem mais, nem menos, a prescrição é x, então vou fazer x, e ponto. Não me interessa para quem é, nem para o que é. É triste, meu amigo, é o que vocês chamam na sociologia de produção em massa de alienação, sei lá. [...] Bem, Jean, tu sabes, na receita não 
diz o que o sujeito tem, diz o que ele tem que tomar. É claro que a gente sabe para o que é, pois a gente já conhece os medicamentos - pela prática, acaba-se quase decorando composições e posologias. Agora, se diz lá, "para Alice", eu não sei se "Alice" é uma moça, uma senhora ou uma cachorra. Tanto faz, é tudo igual: cachorro e gente é tudo igual; o medicamento deve funcionar e ponto. E, por isso, a gente faz e vende (Lucas, bioquímico e farmacêutico, julho e agosto de 2009).

O "tudo igual” que aparece nessas falas é uma das chaves finais para a composição do cão com depressão, e para esse modo de relação entre nós e "os outros humanos". É a partir do reconhecimento de certas propriedades que podem ser compartilhadas entre humanos e animais que se estabelecem modos de identificação e relação, como a convivência no mesmo lar, o uso de roupas, a fisiologia e o diagnóstico e tratamento de certas patologias antes apenas atribuídas aos humanos e, mais recentemente, a administração de medicamentos dessa mesma natureza.

A atenção ao que se pode chamar de problemas comportamentais em animais de estimação e a sua medicalização, segundo Vlahos (2008:451), tem se tornado cada vez mais comum nas últimas duas décadas. Associada a isto, aparece a prática de prescrever para esses animais os medicamentos desenvolvidos para humanos, como o caso do anticonvulsivante GardenalC (fenobarbital - Bayer), utilizado em animais com epilepsia, ou o ansiolítico Diazepam(C) (benzodiazepínico - Roche), de uso comum antes de pequenos procedimentos cirúrgicos, como sedativo, entre tantos outros. Contudo, a estratégia adotada pelos grandes laboratórios farmacêuticos, de acordo com este autor, tem se tornado cada vez mais focada: "vender drogas de modificação comportamental e de estilo de vida especificamente para animais de estimação”. Este é o caso de Slentrol (C e o Anipryl(C), da Pfizer, usados, respectivamente, para cães obesos ou para aqueles que apresentam défices cognitivos, como a perda da memória na idade avançada. Mais especificamente, em termos dos problemas que aparecem nesta pesquisa, há os recentes Clomicalm(C), uma versão canina do Anafranil(C, da Novartis, receitado para humanos, e o Reconcilia $($, uma versão mastigável e com gosto de carne do medicamento que revolucionou o mundo da depressão, o Prozac $@$, da Eli Lilly. Ambos têm indicação para SASA (Ansiedade de Separação em Animais), contudo são recomendados para os cães com depressão.

É interessante pensar que a questão controversa se forma quando começa a ficar evidente que se, por um lado, há um processo visível de singularização do animal de estimação, com suas caracteríticas comportamentais, emocionais 
ou mesmo biotípicas bastante individuais, por outro, aparece a homogenização, como no caso da medicação psi. ${ }^{5}$ À moda daquilo que questiona Pignarre (2006) a respeito dos humanos, de que suas particularidades foram postas em segundo plano com o advento da medicalização, entre os animais a resposta massiva dos psicotrópicos também se torna operante. Com o passar do tempo, grande parte do trabalho de Marcos se resumia a uma simples confirmação: as pessoas já chegavam à loja com uma espécie de diagnóstico pronto, facilitado pelas informações da internet, asseguradas pelas crenças e pela manipulação de medicamentos nos Laboratórios Gemballa ${ }^{6}$

"Você mora em apartamento?", "caminham juntos ou praticam alguma atividade física?", "há algum histórico familiar de diabetes ou colesterol ou de hipertensão?", “problemas cardíacos?”. Para quem faz exames periódicos de saúde, estas não são perguntas estranhas. O que eu estranhava é que elas eram destinadas à formulação do diagnóstico dos animais atendidos. Quando aparecia algum obeso, com problema renal ou constipado, ou ainda aqueles cujo exame hematológico apontava problemas como o colesterol ou o diabetes, entrava em cena um processo da sua distinção em face de uma categoria homogenizadora, visando a uma atenção particularizada. Neste caso, não se tratava genericamente de um cão ou de um gato, tampouco de algum exemplar da raça boxer, beagle ou pitbull. Tratava-se de Fred, Rambo, Mel, Pepper, com todos os seus hábitos sedentários, má alimentação e histórico familiar de algum problema cardiovascular.

Em maio de 2010, a revista Veja dedicou uma matéria especial à medicina de cães e gatos, definindo-a como tão boa quanto a dos seus donos. ${ }^{7}$ Segundo a reportagem, o Brasil já abriga o segundo maior contingente de cães e gatos domésticos, ficando apenas atrás dos Estados Unidos, sendo que as famílias desembolsam cerca de R $\$ 700$ milhões por ano apenas com consultas, medicamentos e vacinas. Este fato tem se tornado cada vez mais comum na medida em que os animais de estimação preenchem as lacunas afetivas de seus donos. Assim, "protegê-los e cuidar deles para que não sofram e vivam por mais tempo fazem parte dessa amizade ancestral" (Veja, 12/05/2010).

Por conseguinte, o segmento dedicado à saúde dos animais, especialmente os domésticos, tem sido igualado ao dos humanos. Alguns exemplos dessas novidades tecnológicas são os holters de glicose e a insulina sem pico de ação que monitoram e medicam o efeito da insulina em cães e gatos diabéticos; o ecocardioma com doppler colorido e tecidual e o holter por telemetria que monitoram e avaliam durante 24 horas o ritmo cardíaco - a contração, a musculatura e a circulação sanguínea - para verificação de arritmias em animais com insuficiência cardíaca; a eletroquimeoterapia, que injeta a medicação diretamente no 
tumor com o uso de uma agulha elétrica, e a criocirurgia, que utiliza nitrogênio líquido para necrose e remoção de tumores - ambas utilizadas em animais com câncer; a tomografia computadorizada de articulação que permite observar em 3D os processos ósseos e de cartilagem; o tratamento com células-tronco utilizado para a regeneração do tecido articular ou como anti-inflamatório em cães e gatos com problemas ortopédicos; a gasometria, que examina a dosagem de cálcio e sódio no sangue, e a hemodiálise usada para os casos graves de insuficiência renal; o tonopen veterinário, que é um aparelho digital usado para a medição da pressão intraocular e o microscópio cirúrgico, que auxilia na realização de microcirurgias de catarata, pálpebra e córnea em animais com problemas oculares. ${ }^{8}$

O que resta disso é avaliar o quanto esses investimentos tecnológicos, com suas promessas milagrosas, atendem, de fato, à demanda pela minimização do sofrimento dos animais. Muito do que se oferece hoje diz mais respeito à conveniência de donos, que assim não precisam lidar diretamente com a animalidade de seus animais.

\section{Ficções úteis}

O diagnóstico da depressão era complexo e controverso: era preciso eliminar os "problemas físicos" e partir para os "problemas psicológicos" para, enfim, medicar os cães. Conforme explicava Marcos, a depressão e a debilidade física resultante de má alimentação e de outras patologias fazem parecer que os cães estão tristes, e isto, para os leigos, é visto como a mesma coisa.

As pessoas adiam a vinda para o veterinário na esperança de que no dia seguinte vão acordar com o seu animal curado por si mesmo. Este é um complicador da saúde de cães ou gatos, já que, adoecidos, eles se alimentam mal, se desidratam e desenvolvem outras patologias, e podem vir a morrer; é uma reação em cadeia. [...] Como veterinário, eu sirvo mais para fazer milagres do que para prevenir um mal. Os bichinhos quase sempre chegam aqui à beira da morte (Marcos, dezembro de 2009).

Este foi o caso de Pink, como também de cerca da metade dos casos que acompanhei ao longo da pesquisa. No caso dela, logo de saída, Marcos pediu que eu estivesse atento aos seus sintomas: o queixo apoiado no chão entre as patas dianteiras, a dificuldade para se levantar ou se locomover, o olhar perdido, os pequenos uivos tristes, patas e rabo apresentando feridas de mordidas. Com isso, ele já pré-diagnosticou a cachorra como depressiva, mas haveria de 
buscar mais certezas. A internação dela se deu por dois motivos: a debilidade física avançada e a necessidade de exames, especialmente pela variável a ser descartada, um novo tumor, resultante daquele retirado anos antes com cirurgia e cessado depois da quimioterapia.

A coleta de sangue, o raio-x ou a biópsia não serviam para o diagnóstico da depressão - eles apenas permitiam o descarte de outras hipóteses e, na falta de questões orgânicas, passava-se àquelas emocionais ou comportamentais. Mas à medida que apareciam os casos com menos históricos complicados e com menos resistência do dono, como foi o da Pink, os diagnósticos se apresentavam quase automaticamente, a partir da caracterização da indisposição, da apatia e da tristeza. "Meu amiguinho está triste", dizia a maioria, "isso é depressão". Ou seja, aquilo que antes era a resposta final, aos poucos começava a se tornar a praxe.

De um modo amplo, ao utilizar como palavra-chave de pesquisa termos como “depressão canina”, "depressão - animais de estimação” em bases de dados que reúnem importantes periódicos de medicina veterinária, nacionais e internacionais (Scielo ou Periódicos CAPES, por exemplo), eu não consegui encontrar trabalhos dedicados a este tema. Assim, à falta de "literatura científica", comecei, nessa época, a me questionar sobre o estatuto dessa depressão canina. Em vez disso, a pesquisa bibliográfica me permitiu descobrir que a medicina veterinária tem considerado como problema crescente na última década a Ansiedade de Separação em Animais (SASA), e esta era motivo de confusão nos diagnósticos. ${ }^{9}$

A SASA pode ser caracterizada por um conjunto de comportamentos indesejáveis, quando animais de estimação, especialmente cães, são deixados sozinhos, ou quando estão afastados da figura de apego (Soares et al., 2010). Esses animais uivam, choram ou latem em excesso, e podem urinar e defecar em locais onde o vínculo é, em geral, estabelecido.

Mesmo assim, na prática, as pessoas chegavam à loja se queixando de que seus cães estavam com depressão. Foi quando eu mudei minha forma de abordagem em relação ao tema: eu deixei de questionar se existe depressão canina e tomei-a como um fato, passando a perguntar às pessoas como elas sabiam que os seus animais estavam sofrendo com ela. As respostas novamente se apoiavam em comportamentos aparentes e nas matérias que eles encontravam através de pesquisas que faziam no Google. Dessa forma, o que começou a ficar claro para mim é que, enquanto eu procurava explicações científicas para a depressão canina, as suspeitas ou os disgnósticos trazidos pelas pessoas à loja frequentemente vinham de blogs, periódicos, programas de televisão ou mesmo em função da recomendação de amigos, como aquilo que Brown (2010) chamou de epidemiologia popular. 
Seguindo essa pista, comecei a consultar os blogs que eram recomendados pelos frequentadores da loja. Um deles, o Dog’s Times, trazia definições bastante complexas sobre a depressão canina. ${ }^{10}$ Segundo ele, o fato de que cães podem sofrer de estados depressivos foi ignorado por muito tempo pelas pessoas e pelos veterinários $-\mathrm{a}$ isto se acrescentando fatores de envelhecimento, motivadores da diminuição das atividades treinadas ou brincadeiras desses animais. Mas esse quadro mudou com o estudo das patologias do comportamento que, entre outras coisas, passou a entender que a depressão em cães

é um estado particular das estruturas emocionais, que pode se manifestar clinicamente de várias maneiras [...] o cão deprimido é um indivíduo apático, inativo, que não se interessa absolutamente pelo que o rodeia e que manifesta um estado de angústia permanente. No entanto, este estado pode se alternar com outros de agitação, característicos de uma das formas clínicas.

Dentre essas formas clínicas nas quais se manifesta a depressão canina, o blog caracteriza especialmente três: 1. a depressão de reação, "causada por um estresse ou choque emocional grave", em que "o organismo responde a uma sobrecarga de estímulos negativos", como uma agressão, por exemplo, com estados transitórios de depressão, que duram de oito a dez dias, quando o animal não precisa ser medicado; 2. a depressão de regressão, classificada pelo Dog's Times como muito grave, "caracterizada pela perda de comportamentos adquiridos" (especialmente de higiene ou ordens aprendidas em adestramento) e "pelo regresso a comportamentos infantis” (em particular, a exploração oral). Neste caso, "o animal cessa, quase totalmente, de se movimentar, chora durante horas, faz as necessidades debaixo de si mesmo e engole tudo o que encontrar nos seus escassos deslocamentos”. Aqui, segundo a orientação do blog, haveria a necessidade de intervenção psicotrópica à base de inibidores seletivos de recaptação da serotonina, como é o caso da fluoxetina; 3. por fim, aparece a depressão cíclica, entendida como relativamente frequente, especialmente entre fêmeas. Seus ciclos duram entre 15 dias e dois meses e se caracterizam pela "indiferença, tristeza, anorexia, perda dos comportamentos aprendidos".

Noutro blog, as características de depressão canina eram associadas àquelas encontradas na literatura científica como SASA: "o comportamento de apego é essencial para a sobrevivência de animais sociais. É um mecanismo de coalizão social". ${ }^{11}$ Segundo o veterinário Mauro Lantzan, autor da matéria, deve-se então estar atento ao que ele chama de período de socialização entre o cão e seu dono, que é o período fundamental para a determinação de hierarquias, comunicação 
e confiança entre ambos. Caso o animal fique muito dependente do seu dono, períodos de separação, como as idas para o trabalho, podem desencadear esses comportamentos depressivos no cão:

a depressão, ou estado depressivo, pode estar relacionada à ansiedade e acontece quando o animal é exposto a situações de estresse, em caráter crônico ou de forma traumática, passando a manifestar sinais de inabilidade em executar suas funções biológicas, apatia, inapetência e isolamento social (grifos originais).

$\mathrm{Na}$ sequência, eu encontro a explicação de que há raças mais propensas à depressão, em especial aquelas "selecionadas para companhia", mas que, mais determinante que isso, deveria ser a consideração de que mudanças bruscas de rotina, ausência dos próximos no convívio - outros cães ou humanos - eram os principais fatores desencadeantes da depressão, pois os tornam "vulneráveis ao estresse". No entanto, e, sobretudo, o leitor deveria ter a consciência de que "cada animal é um ser único e deve ser encarado como um indivíduo dotado de características próprias" ("Ser único”, "indivíduo com características próprias”, aquelas expressões já haviam se sobressaído em outras situações na loja). Continuei minha leitura:

a depressão deve ser encarada como um processo complexo. Uma vez diagnosticado o problema e definida a sua causa, o tratamento pode incluir medicamentos antidepressivos, como Prozac, além de mudanças no manejo. Remédios homeopáticos e Florais de Bach contribuem para o restabelecimento emocional do cão deprimido e podem ser prescritos pelo terapeuta. Melhorar a qualidade de vida do animal e cuidar do seu bem-estar é também importante. Essa é a base da terapia comportamental.

Parecia que em cada linha lida eu encontrava mais um elemento a ser discutido, somando-se "processo complexo", "Prozac", "remédios homeopáticos e Florais de Bach", "restabelecimento emocional do cão deprimido", "prescritos pelo terapeuta" ou "qualidade de vida do animal". Tudo isso fazia perfeito sentido, ao menos no conjunto dos diagnósticos que chegavam à loja ou os que eram feitos lá. Mas a questão é que aparentemente havia nesses blogs uma tradução de elementos característicos da SASA para falar da depressão canina, a isto acrescentando-se uma leitura que era conveniente em relação aos estados apresentados pelos cães e aos interesses de seus donos. 
A ideia de depressão canina parecia simplificar o entendimento entre os donos, já que se tratava de uma espécie de termo comum a certa camada da população que crescentemente tem feito uso de sistemas explicativos de mundo centrados no ego ou no subjetivismo - pelo reconhecimento de uma interioridade (Duarte \& Carvalho, 2005) Em vez disso, ela promovia as pet shops, pois as colocava "na onda" da humanização dos animais (Kulick, 2009), pois estava associada à reorganização comportamentalista das psicoterapias, que passam a supor a exigência de medicamentos psicotrópicos (Vlahos, 2008; Pignarre, 2006). A tristeza e a melancolia não são a depressão. Mas a depressão se torna o nome geral para ambas. E isto não operava como uma simples substituição de termos.

Nos modos tradicionais de reconhecimento de uma doença, já bem apontou Langdon (2003), há uma preeminência de explicações cosmológicas em que as pessoas se compreendem como afetadas ou invadidas por algo externo a elas: um feitiço, um mal-olhado, um efeito do mundo sobre si. De outro modo, na maior parte dos modelos biomédicos, uma doença é explicada como resultado de processos de desajustes fisiológicos, sejam eles de ordem congênita ou adquiridos por meio de bactérias e vírus. O primeiro, no mundo da crença; o segundo, no mundo da prova. E em ambos uma brecha para a desresponsabilização pelo sofrimento. Afinal, as pessoas são atacadas por micro-organismos e feitiços ou têm seus destinos traçados no nascimento, seja por suas divindades, seja por seus genes (Segata, 2010).

Tristeza e melancolia são conceitos para estados ou modos de constituição do ser bastante complexos, mas solúveis, por serem metafísicos. Se uma pessoa é ou está triste ou melancólico, isso é parte dela, quea pode se reconhecer bem ou feliz assim. Contudo, se ela está ou se percebe em desacordo com isso, é sua responsabilidade agir em função de se colocar em outros estados. Já a depressão - esse conceito de disputa entre a psicologia, a psiquiatria e a neurologia - traz em si o aspecto negativo da patologia e, ao mesmo tempo, a possibilidade de fuga da responsabilidade pelo sofrimento. ${ }^{12}$ Depressão, na lógica biomédica, é uma questão de desordem da natureza psíquica ou neuroquímica - não é uma questão de escolha, mas de "ser escolhido". Dessa forma, isto desresponsabiliza o sujeito, pois não é ele que deve se desfazer disso, é preciso que algo ou alguém o faça por ele. E é aí que, entre outras coisas, as pessoas autorizam ser medicados. Não é um problema a ser resolvido pelo sujeito, mas pela fluoxetina. Em uma fórmula resumida, tristeza e melancolia estão para o agente tanto quanto a depressão está para o paciente.

É nesse caminho que Roudinesco (2000) faz sua defesa da psicanálise. Para ela, diferentemente das neurociências, das psicologias de modelo cognitivo ou da 
própria psiquiatria, a psicanálise se focaria no sujeito-agente que, ao se reconhecer como constituído pela depressão, passaria no processo analítico a se reconhecer também como aquele que potencialmente pode se constituir nela ou por ela. Enfim, um sujeito melancólico. Veja-se isso como positivo, tomando como contraponto um paciente objeto da depressão. Em termos mais gerais, Roudinesco (2000) nos transmite a ideia de que haveria um processo de desagenciamento dos sujeitos ao buscarem cada vez mais formas de tratamento que não exijam de si próprios um processo de análise, o que pode, é claro, ser lido como outras formas de agenciamento, como na relação estabelecida entre Bia e Pink. ${ }^{13}$

No que se segue a isso, os estados apresentados pelos cães, segundo a literatura médico-veterinária, poderiam ser de SASA, caso fossem profundamente investigados, ou de qualquer outra patologia que os colocasse em aparente tristeza e apatia. Mas a depressão tornou-se uma síntese provisória resultante de uma rede por demais complexa que permite o entendimento comum e ao mesmo tempo move ações. Com o modo de vida contemporâneo e com as facilidades do seu tratamento, especialmente possibilitadas pela imensa mobilização de meios de financiamento de suas formas de tratamento medicamentoso (Roudinesco, 2000; Pignarre, 2001, 2006), a depressão canina, tal qual a humana, virou uma epidemia.

A depressão canina poderia ser considerada, assim, uma espécie de ficção útil, ou seja, um dispositivo que permite o conhecimento e a organização de certas experiências no mundo, o que diz respeito às classificações que nos levam a construir uma determinada realidade na organização de fatos empíricos. Por alto, esta é uma ideia que aparece desde a filosofia kantiana, como aquilo que traz solução a problemas factuais, aquilo que os norte-americanos costumam chamar de folk psychology, em que a possibilidade de comunicar, conhecer e agir se dá na suposição de partilha de significados e nas crenças elaboradas a partir de experiências cotidianas (Davidson, 1980; Zilhão, 2001).

Assim, os cães com depressão são contingentes, ou seja, eles resultam de novos conhecimentos engendrados com o surgimento de novos conceitos, novas técnicas e novos sujeitos de conhecimento que podem ser apreendidos na forma de uma síntese sempre provisória (Foucault, 2005; Simmel, 2006). Sua importância não se dá aqui pelo seu valor de verdade, mas no sentido de serem, de fato, um fenômeno patológico reconhecido pela literatura médico-veterinária, compondo novos índices epidemiológicos. O que eu considero interessante é que as pessoas se organizam em torno da sua existência.

Humanos e cães são descontínuos, mas equivalentes: a nossa identificação é nutrida pela forma aparente desse mal - a apatia, a falta de apetite ou a melancolia, 
e o tratamento nos aproximam nas correlações orgânicas/naturais. Assim, se no caso dos humanos existe no diagnóstico da depressão a autorização para atender a determinadas demandas, como o uso da medicação psicotrópica, por analogia, por que não medicalizar os cães também? De um modo geral, parece que os comportamentos "animalescos" dificultam a relação e fazem com que esses bebezinhos ou lindinhos voltem ao seu "estado natural", de simples cães ou gatos. E, sem os "manejos adequados", sem o tratamento dessas "pulsões", dilui-se a humanidade deles. Os equipamentos médicos, os diagnósticos e os tratamentos com fármacos parecem facilitar uma diplomacia entre as espécies.

Recebido em 15/10/2012

Aceito em 13/11/2012

Jean Segata é bacharel em Psicologia (UNIDAVI, 2004), mestre em Antropologia Social (PPGAS/UFSC, 2007) e doutor em Antropologia Social (PPGAS/UFSC, 2012). Atualmente é bolsista de pós-doutorado do CNPq no PPGAS/UFSC e docente na UNIDAVI (Centro Universitário para o Desenvolvimento do Alto Vale do Itajaí), onde coordena o Núcleo de Estudos em Antropologia. 


\section{Notas}

1. Uma primeira versão deste texto foi apresentada com o título "Uma Nova Epidemia: a depressão canina e os seus dispositivos", em um GT pioneiro na área - "Animais e humanos em contextos urbanos e rurais: novas perspectivas sobre relações interespecíficas”, sob a coordenação de Felipe Ferreira Vander Velden (UFSCAR) e Ciméa Barbato Bevilaqua (UFPR). Agradeço a eles e aos demais participantes pelos valiosos comentários à apresentação. Anterior a isso, o presente trabalho tem como essência o terceiro capítulo de minha tese de doutorado em Antropologia Social, defendida em 2012 no PPGAS/ UFSC, com o título "Nós e os Outros Humanos, os animais de estimação”. Agradeço aos membros da banca, Guilherme da Silva e Sá (UnB), Eduardo Viana Vargas (UFMG), Oscar Calávia Sáez (UFSC), Jeremy Loup Deturche (UFSC) e Alberto Groisman (UFSC) por suas avaliações e recomendações e, em especial, a Theophilos Rifiotis (UFSC), que há muitos anos orienta meus trabalhos. Por fim, agradeço a CAPES pela concessão de Bolsa PDEE durante o doutorado, permitindo minha estadia em Paris para um estágio no Laboratoire d'Anthropologie Sociale - LAS, sob a orientação de Philippe Descola, a quem também dirijo meus agradecimentos, juntamente a Noëlie Vialles, Frédérick Keck e Vanessa Manceron.

2. Os Laboratórios Gemballa são a mais antiga e uma das mais importantes referências em redes de farmácia e manipulação na cidade de Rio do Sul e na região.

3. Ver, por exemplo: <http://www.senamadureira.com/midia15.html>, acesso em maio de 2010; <http://www.petfriends.com.br/veterinario/dicas_filetti_prenatal.htm>, acesso em maio de 2010. Ver também a matéria intitulada "A Mordomia das Futuras Mamães”, da revista Veja, ed. 1828, de 12 de novembro de 2003.

4. Segundo as mesmas autoras, apesar de ter ocorrência comum, sua incidência e distribuição permanecem ainda desconhecidas, mas "especula-se que sua manifestação seja uma característica evolutiva herdada pelo cão doméstico”. A vantagem evolucionária, neste caso, se daria pelo fato de que a "fêmea dominante" poderia caçar, enquanto outras, as mais fracas do grupo, fariam o trabalho de amamentação. Pois bem, parece que no “mundo animal”, tal qual nos modelos capitalistas tão discutidos nas ciências humanas, é preciso que alguém dê conta das rotinas de manutenção da vida cotidiana (e natural), à medida que outros fazem o trabalho fora de casa (cultural e provedor). No momento, isto fica apenas como uma anedota, mas é interessante problematizar uma questão: ou bem nós, os antropólogos, questionamos os "modelos naturais" e, como humanos, nos colocamos fora da questão, ou bem os veterinários e os demais cientistas naturais "culturalizaram" os seus discursos ao reafirmaram modelos de gênero: quem é forte ou quem é provedor até a afirmação da heteronormatividade. Ainda quanto a este aspecto, cabe mencionar uma questão latente, e que engloba depressão, gravidez e feminino, e que faz eco com aquilo 
que Tornquist e Maluf (2009:442) problematizam ao discutirem o trabalho de Silveira (2000) sobre as mulheres que narravam seus dramas cotidianos, seus ataques e sensações físicas e emocionais a partir daquilo que se chamava "doença de nervos”. Pelo fato de não terem suas queixas ouvidas pelos médicos, elas investiam no uso de calmantes. Essas medidas tornavam-se um idioma que expressava dimensões pessoais e sociais da mulher fraca, nervosa, e traziam à tona configurações hierárquicas de gênero.

5. Pignarre (2006:18) mostra isto com propriedade ao tratar do que ele chama de medicalização do social. Ele questiona: "Un patient souffrant d'un trouble mental ou psychologique peut-il être consideré comme faisant partie d'un 'groupe' rassemblant ceux qui présentent les mêmes symptômes que lui, ou faut-il considérer qui'il n'existe que des 'sujets tous différents'?".

6. Isso porque havia na época, no Brasil, restrições para a comercialização de psicotrópicos e medicamentos especiais para animais de estimação, como esses fabricados pelo Novartis ou pela Eli Lilly. Ver também o interessante trabalho de Fraser (2001): The nature of Prozac. Nele, a autora trata da revolução causada por esse medicamento. Para ela, as explicações do funcionamento do cérebro que acompanham este medicamento trouxeram novos entendimentos que validavam o seu uso. Sobre o estatuto da droga e do medicamento, especialmente psicotrópicos, ver ainda Vargas (1998, 2006), Pignarre (1999), Akrich (1995), Azize (2010) e Lakoff (2008). Em particular, este último traz uma interessante apresentação do caso argentino, de quando o DSM-III acionou a indústria farmacêutica para o tratamento dos males psi, antes território da psicanálise.

7. “Tudo pela Saúde deles”. Revista Veja, ed. 2164, ano 433(19), p. 140-146, $12 / 05 / 2010$.

8. Cf. Veja (maio 2010): as novas tecnologias para diagnóstico e tratamento dos animais de estimação chegam associadas a um gama de novidades farmacológicas. Na próxima seção destaco o investimento nos psicofármacos: ansiolíticos, antidepressivos ou inibidores de apetite para animais de estimação. No Brasil e nos Estados Unidos, entre 2003 e 2009, o número de cães que tomavam algum medicamento passou de 25\% para 77\%. A mesma reportagem ainda traz um indicativo de que $42 \%$ dos cães têm problemas comportamentais e, no todo, eles apresentam nove vezes mais distúrbios psicológicos do que os humanos. Cf. também: Revista Superinteressante, ed. 263, p. 54-63, março de 2009, e Canine Inherited Disorders Database - CIDD <www.upei.ca/cidd/intro.htm $>$ acesso em maio de 2011.

9. Os termos utilizados para a busca de materiais eram combinações entre as palavras “depressão”, “cães”, “transtorno depressivo”, “depressão canina”, “animais de estimação”. Em alguns casos, esses termos eram lançados diretamente no Google ou no Google Acadêmico, como foi também essas combinações em inglês e em francês. Nesse caso, era mais fácil encontrar textos que tratavam do tema, exceto pelo fato de que o critério para 
atender a "cientificidade" do trabalho era a de que ele estivesse publicado em revista da área da medicina veterinária, ligada a alguma faculdade ou com ISBN. Não foi o caso. Os resultados da pesquisa apenas direcionavam a blogs ou sites de informações gerais - a excessão, eram aqueles institucionais, de laboratórios farmacêuticos, como discutido adiante.

10. Cf. "Depressão": <http://www.dogtimes.com.br/depressao.htm>, acesso em outubro de 2009.

11. "Ansiedade de Separação em Cães": <http://www.saudeanimal.com.br/artig130. htm>, acesso em maio de 2009.

12. Sobre a disputa entre as discussões subjetivistas e fisicalistas da depressão, ver Azize (2008).

13. As duas moravam em um apartamento, e sempre que Marcos responsabilizava Bia pelo sofrimento de Pink acusando-a de pouca dedicação a passeios pela rua e de não dispor de mais tempo livre para brincadeiras, Bia se desresponsabilizava em um contradiscurso que tinha sempre como eixo central um questionamento: "mas o que eu posso fazer se ela tem depressão?”. A fluoxetina, recomendada por Marcos, era a única ação tomada em um tratamento que deveria incluir, primordialmente, mudanças de hábito ou caminhadas ao ar livre, que tirassem minimamente ambas, Bia e Pink, do apartamento onde viviam. Mas, como se pergunta Roudinesco (2000), para que se preocupar com tanta coisa, posto que a neurobiologia tem a resposta certa e a indústria farmacêutica, a solução? Parece que a natureza nos salvou - às suas desordens, a química traz as soluções. 


\section{Referências bibliográficas}

AGAMBEN, Giorgio. 2009. “O Amigo”. In: O que é o Contemporâneo? e outros ensaios. Chapecó: Argos. p. 77-92.

AKRICH, Madeleine. 1995. "Petite Anthropologie du Médicament". Techniques et Culture, n. 25-26:129-157.

AZIZE, Rogério. 2008. "Uma Neuro-Weltanschauung?: fisicalismo e subjetividade na divulgação de doenças e medicamentos do cérebro”. Mana, v. 14, n. 1:7-30.

2010. A Nova Ordem Cerebral: a concepção de “pessoa” na difusão neurocientífica. Tese de doutorado, Rio de Janeiro, Programa de Pós-Graduação em Antropologia Social/ Museu Nacional/ UFRJ,

BROWN, Phil. 2010. “Retour sur l'Epidemiologie Populaire”. In: Madeleine Akrich; Yannick Barthe \& Catherine Rémy (eds.). Sur la Piste Environnementale: menaces sanitaires et mobilisations profanes. Paris: Mines Paris. p. 53-88.

CORRÊA, Ana et al. 2005. "Babesiose Canina: relato de caso". Revista Científica Eletrônica de Medicina Veterinária, FAEF, Garça/SP, ano 3, n. 4:167-171.

CUNHA, Guilherme Nascimento. 2009. Estudo da Viabilidade do Uso da Punção Biópsia Aspirativa por Agulhas Finas comparada ao da "Tru-Cut", em Testículo de Cães. Tese de doutorado, Jaboticabal, Faculdade de Ciências Agrárias e Veterinárias, Universidade Estadual Paulista.

DAVIDSON, Donald. 1980. Essays on Actions and Events. Oxford: Clarendon Press.

DUARTE, Luis Fernando \& CARVALHO, Emilio. 2005. "Religião e psicanálise no Brasil contemporâneo: novas e velhas Weltanschauungen”. Revista de Antropologia, v. 48 (2): 473-500.

FOUCAULT, Michel. 2005. A Verdade e as Formas Jurídicas. 3. ed. Rio de Janeiro, Nau Editora.

FRASER, Marion. 2001. "The nature of Prozac". History of the Human Sciences, 14 (3): 56-84.

HARAWAY, Donna. 2011. "A Partilha do Sofrimento: relações instrumentais entre animais de laboratório e sua gente”. Horizontes Antropológicos, Porto Alegre, ano 17, n. 35: 27-64.

KULICK, Don. 2009. “Animais Gordos e a Dissolução das Fronteiras entre as Espécies”. Mana 15 (2): 481-508. 
LAKOFF, Andrew. 2008. La Raison Pharmaceutique. Paris: Les Empêcheurs de Penser en Rond/Seuil.

LANGDON, Esther Jean. 2003. "Cultura e Processos de Saúde e Doença”. In: Leila Jeolás (org.). Anais do Seminário sobre Cultura, Saúde e Doença. Londrina: [S.E.]. p. 91-107.

LOPES, Maria Denise \& MARTINS, Lílian Rigatto. 2005. "Pseudociese Canina”. Revista Brasileira de Reprodução Animal, Belo Horizonte, v. 29, n. 3/4: 137-141.

PIGNARRE, Philippe. 1999. O que é o Medicamento?: um objeto estranho entre a ciência, mercado e sociedade. São Paulo: Editora 34.

2001. Comment la Dépression est devenue une Épidémie. Paris: La Découverte.

2006. Les Malheurs des Psys: psychotropes et médicalisation du social. Paris: La

Découverte.

ROUDINESCO, Elisabeth. 2000. Por que a Psicanálise? Rio de Janeiro: Zahar.

SEGATA, Jean. 2010. “A Doença e a Inocência: vitimização na Educação Infantil”. In: J. Segata; N. Machado \& J. Nasário (orgs.). Educação Física: transversalidades. Rio do Sul: Editora UNIDAVI. p. 49-65.

SIMMEL, Georg. 2006. "O Âmbito da Sociologia”. In: Questões Fundamentais da Sociologia. Rio de Janeiro, Zahar. p. 07-38.

SOARES, Guilherme et al. 2010. "Estudo exploratório da síndrome de ansiedade de separação em cães de apartamento”. Ciência Rural, Santa Maria, v. 40, n. 3: 548-553.

SPIVAK, Gayatri. 1998. “Can Subaltern Speak?” In: Patrick Willians \& Laura Chrisman (eds.). Colonial Discourse and Post-Colonial Theory: a reader. NY and London: HarveterWeatsheat. p. 66-111.

TORNQUIST, Carmen Suzana \& MALUF, Sônia Weidner. 2010. "Nervos e Nervosas no Contexto das Aflições Contemporâneas: entrevista com Maria Lucia da Silveira". In: ___ (orgs.). Gênero, Saúde e Aflição: abordagens antropológicas. Florianópolis: Letras Contemporâneas. p. 441-457.

VLAHOS, James. 2008. “Animais de Estimação Movidos a Drogas”. Revista Latinoamericana de Psicopatologia Fundamental, v. 11 (3): 449-469.

VARGAS, Eduardo Viana. 1998. “Os Corpos Intensivos: sobre o estatuto social do consumo de drogas legais e ilegais”. In:, L. F. Duarte \& O. F. Leal (orgs.). Doença, Sofrimento, Perturbação: perspectivas etnográficas. Rio de Janeiro: Fiocruz. p. 121-136. 
. 2006. “Uso de Drogas: a alter-ação como evento". Revista de Antropologia, São Paulo, USP, v. 49 (2): 581-623.

ZILHÃO, António. 2001. "Psicologia Popular, Teoria da Decisão e Comportamento Humano Comum”. Disputatio, p. 123-145. 


\section{Resumo}

A humanização dos animais, especialmente aqueles de estimação, é tema corrente em nossos dias. Ela é motivo de reportagens, debates envolvendo economistas, psicólogos, juristas, médicos, religiosos, filósofos ou antropólogos, como também o é para a expansão de mercados, para investimentos políticos ou para inspiração artística. Mas como é produzida a humanidade desses animais? Quando ou até onde eles são humanos? O objetivo deste trabalho é o de fazer aparecerem essas negociações e limites, a partir da análise de um caso de diagnóstico e tratamento de depressão atribuído a uma cachorra. Sustenta-se aqui que o que tratamos por humanização dos animais não se nutre simplesmente da equivalência de elementos culturais como os nomes humanos, as roupas, os cuidados, viverem nos mesmos lares ou motivarem discussões sobre alguns direitos e moralidades. Além do mais, ela se nutre, igualmente, daqueles elementos que imputamos ao domínio da natureza, como alguns instintos que precisam ser modulados ou uma biologia equivalente que permite o diagnóstico de problemas orgânicos e a sua medicalização.

Palavras-chave: Depressão, humanos e animais, identificação, relação

\section{Abstract}

The humanization of pets is a current topic today. It is the subject of broadcasts, debates involving economists, psychologists, lawyers, doctors, clergy, philosophers and anthropologists, as well for the markets' expansion, investment on politics and artistic inspiration. Although, how is produced the "humanity" of these animals? When or how far are they human beings? The main goal of this work is to bring up these negotiations and limits from a case analysis of diagnosis and treatment of depression assigned to a female dog. It is also defended that what we address as humanization of animals is not only nurtured of the equivalence of cultural elements, such as human names, clothing, care, living in the same homes or motivating discussions on some rights and morals. Furthermore, it's nurtured of those elements that we attribute to the field of nature as some instincts that need to be modulated or an equivalent biology that allows the diagnosis of organic problems and their medicalization.

Keywords: Depression, human beings and animals, identification, relationships 